\title{
Strategies to Motivate Children to Engage in Leisure Reading: Qualitative Insights from Nigerian Children
}

\author{
Isang U. Awah \\ Department of Social Policy and Intervention, University of Oxford, Oxford, United Kingdom
}

\begin{abstract}
Some research done in the Western world indicates that children's reading engagement is affected by certain factors and that children can be impacted in such a way that they will choose to engage in leisure reading. This paper, which arises from a study that explored the reading habits of a group of 9-12-year-olds in a book club in Nigeria, examines the factors that affected the reading engagement of the participants and suggests evidence-based strategies that could motivate children to engage in leisure reading. Through an interpretivist theoretical perspective, the study gathered data using the methods of collage making, observation, questionnaire, and interviews, and analysed them through inductive thematic analysis. Findings indicate that the participants read for pleasure, though their level of reading engagement differed. Findings also reveal that the reading engagement of all the participants may have been, in varying degrees, influenced by different factors such as the pedagogy of reading, access to reading materials, the reading environment, and the availability of social networks that support leisure reading. Insights from the study could guide on practices that strengthen children's engagement in leisure reading.
\end{abstract}

Index Terms-children's leisure reading, affecting factors, motivating strategies, reading engagement, Nigerian children

\section{INTRODUCTION}

This paper reports on the factors that affected the reading habits of a group of 9-12-year olds in a book club in Nigeria and also suggest evidence-based strategies that could motivate children to engage in leisure reading. It arises from a qualitative study which explored the extent to which the children read; how, what, when and why they read when they did leisure reading at home, in school and the book club; and the different factors that affected their reading motivation and reading engagement. 'Leisure reading', used here interchangeably with 'recreational reading' and 'reading for pleasure', is the volitional act of reading that is undertaken by individuals and groups because of the feeling of enjoyment or satisfaction that they get from the act (Cremin, Mottram, Collins, Powell, \& Safford, 2014), and 'reading' in this paper primarily refers to 'leisure reading'. Some studies have linked the poor educational outcomes in Nigeria to the reading habits of Nigerian children and argued that the children do not engage in leisure reading. However, there has been no in-depth investigation of either the extent to which Nigerian children read or the different factors that impact on their reading habits. This study therefore addressed these gaps. While this paper will briefly discuss the extent to which the participants read, its focus will be on the different factors that affected the participants' reading engagement and the strategies that could be used to motivate Nigerian children to read. It will also examine the relevance of factors identified by studies in the United States and the United Kingdom to the participants' reading habits. This paper was previously published in a conference proceeding as "'We Love Reading, But...': Nigerian Children on Factors that Affect Their Reading Habits" with DOI: 10.36315/2019v2end035, but has been substantially revised with expansions of key ideas, examples, and elaborations.

\section{LITERATURE REVIEW}

Nigeria, which has an estimated population of over 200 million people, is Africa's most populous country (Data World Bank, 2020). However, about half of the country's population live below the poverty line (Data World Bank, 2016), and in the past decades, student achievement has been repeatedly low (Adesulu, 2018; World Bank Report No: 115391-NG, 2017). The absence of a reading culture, i.e. regular engagement in leisure reading, is often cited as being responsible for the low student achievement in Nigeria (Ihejirika, 2014; Makinde, 2018), and educationists have made repeated calls for the promotion of recreational reading in Nigerian children and youths (Adesulu, 2016; Adekunle, 2017).

Some studies in Nigeria support the argument that Nigerian students have a poor reading culture (Olasehinde, Akanmode, Alaiyemola, \& Babatunde, 2015; Tunde-Awe, 2014). Sotiloye and Bodunde (2018) argue that most students only read to pass examinations and hardly engage in any reading outside school books. However, other studies suggest that the claims that Nigerian students have a poor reading culture may be inaccurate (Haliru Abdulkarim, 
Mohammed \& Dangani, 2015; Aramide, 2015), but these contradict Oyewusi and Ayanlola's (2014) findings that most students preferred to read for pleasure than for academic purposes. While these studies differ in their findings, most of them seem to emphasise the positive relationship between a reading culture and academic performance. This is not unusual as research suggests a strong link between leisure reading and student achievement.

Recurring evidence indicates that leisure reading offers many benefits including a positive impact on academic achievement (Sullivan \& Brown, 2015), reading proficiency (Clark, 2013), increased general knowledge (Cunningham \& Stanovich, 1998), vocabulary development (Chew \& Krashen, 2017), writing ability (Barrs \& Cork, 2001; Parry \& Taylor, 2018), children's attainment and their attitudes to reading (Cremin et al., 2014), and positive emotional and social consequences (Mar, Oatley, \& Peterson, 2009). In addition to providing pleasure, reading literature helps in cultivating imagination (Cliff Hodges, 2010a; Cremin, 2015).

Despite the benefits that leisure reading offers, many children and adolescents who can read are not engaged readers (Mullis, Martin, Kennedy, \& Foy, 2007). This is not altogether surprising as studies carried out in Western countries suggest that children's engagement with leisure reading is influenced by many factors, some of which are the methods of teaching literature in school (Rosenblatt, 1978/1994), choice of texts (Clark \& Phythian-Sence, 2008), and reading aloud (Layne, 2015; Cremin et al., 2014). Rosenblatt (1978/1994) argues that if a literature text is introduced to children with a question on what they learn from the text, the children will adopt an efferent, fact-accumulating attitude when reading the text, and may likely not derive pleasure in reading the text. On the other hand, when reading is done for the sheer pleasure that it gives and nothing is expected of the child except to enjoy the stories, the child is likely to associate reading with pleasure and engage in it repeatedly (Pennac, 2006; Gordon, 2018).

Although leisure reading is a choice, children can be impacted in such a way that they will more likely than not make the choice to read (Cremin et al., 2014; Layne, 2009). For instance, allowing children and young people to choose or self-select what they read leads to a positive attitude towards reading and accordingly, better engagement in, and enjoyment of leisure reading (Clark \& Phythian-Sence, 2008; Cremin, 2007). It is also important to recognise and respect the range of reading that children engage in as many young readers are disempowered and inhibited in their development as habitual readers due to school definitions of literacy (Coles \& Hall, 2002; Manresa, 2018). Though choice and interest empower and positively influence children to read, the choice could have a negative impact if it is provided haphazardly (Clark \& Phythian-Sence, 2008).

Another factor identified to impact children's reading engagement is reading aloud (Cremin et al., 2014, Lockwood, 2008). When teachers read aloud to their students, they instil a love of reading in the students, and the students are likely to get hooked on books as they associate reading with pleasure (Layne, 2009, 2015; Cliff Hodges, 2011). However, despite the possible benefits, reading aloud also has the potential to bore children and take away the pleasure from reading if the book seems never-ending and requires memory for descriptive detail rather than for plot-filled action (Chambers, 1993).

Other factors revealed to play a critical role in leisure reading are access to engaging and suitably challenging texts, an enabling adult, the reading environment, and social networks that support leisure reading. Suitable texts must be available and accessible to children when they want to read them (Chambers, 1991; Clark \& Douglas, 2011). Chambers (1991) also argues on the importance of the reading environment which he describes as being made up of the place (setting), the availability of books, time available for reading, interruptions the reader may experience, the mood of the reader, and the attitude of the reader. According to him, the reading environment greatly influences the reader's experience of reading. The argument for the right setting is supported by Layne (2009) and Cremin et al. (2014).

A child's reading engagement can also be positively influenced by the presence of an enabling adult, that is, an adult who loves books and recreational reading, knows children's literature, discusses books regularly with the child in a manner the child finds engaging and appealing, knows the child's reading tastes, suggests suitable and engaging books to the child, and reads aloud to the child (Layne, 2009, 2015). Studies on successful literacy achievement often appear to feature either a teacher or a parent (Cremin et al., 2014). The positive impact of an enabling adult on a child's reading engagement is strongly supported by Klauda (2009) and Cliff Hodges (2010b).

In addition to the factors discussed above, social networks and affordances that support children's leisure reading such as libraries and literary programmes have also been identified to play a major role in nurturing children's love for reading and their development of a reading culture (Campbell-Hicks, 2016; Adkins \& Brendler, 2015). Reading motivation is as much intrinsic as it is contextual, and having networks and affordances that support leisure reading can motivate young adolescents to read (Loh, Ellis, Paculdar \& Wan, 2017; Francois, 2015).

Some reading-related studies in Nigeria have suggested that Nigerian children's reading habits are affected by factors such as a minimal experience of print immersion, absence of collaboration between the home and school in the provision of reading empowerment for the child, a hostile examination system, and the imposition of an ill-motivated and ill-equipped reading teacher (Onukaogu, 2001); the lack of intrinsic motivation for reading, lack of choice of what to read, negative attitude to reading, and competing activities (Ilogho \& Michael-Onuoha, 2015); the escalating level of poverty, a growing culture of TV viewership, unidentified dyslexics (Okebukola, 2005), and shortage of reading materials, a dearth of libraries, internet usage, and lack of encouragement from parents (Olasehinde et al., 2015). However, there appears to be no in-depth investigation of the factors that affect the reading engagement of Nigerian children. Additionally, the reading-related studies carried out in Nigeria had participants who were students in either 
secondary or tertiary institutions. Hence, there is a need for an in-depth study of the factors that affect the leisure reading practices of primary school children in Nigeria. Addressing this gap is important as studies indicate that primary and elementary years are critical periods in the formation of lifelong reading habits (Cullinan, 2000; Cunningham \& Stanovich, 1998).

This study, therefore, explored reading for pleasure done by a group of 9-12-year-olds in a book club in Nigeria to shed light on the children's reading habits and the factors that affected their reading engagement. However, this paper shall majorly discuss the factors that affected the participants' reading engagement and shall suggest strategies that could be used to motivate children to read.

\section{TheORETICAL APPROACH, MethodOLOGY AND METHODS}

\section{A. Theoretical Approach}

The epistemological stance that this study was based on is constructionism. Constructionism holds that all knowledge is contingent upon human practices, and is constructed in and out of the interaction between human beings and their world, and also developed and spread in an essentially social context (Crotty, 1998). Based on the exploratory nature of the research and the constructionist epistemological stance, an interpretivist theoretical perspective was adopted. This perspective encourages the researcher to recognise data as text to be interpreted. Also, individual participants interpreted their engagement with reading for pleasure and the factors surrounding it based on their personal experiences, and the understanding of the participant's engagement with reading for pleasure came from the interactions with them and the data they provided.

\section{B. Methodology}

The methodology used was a case study. The case or unit of analysis for this study was the Krown Book Club (KBC) in Nigeria, and the main participants were the 9-12-year-olds that attended KBC during two different vacation periods in 2017. A few participants were slightly outside the age range. The research was carried out in a book club rather than in a primary school because the researcher wanted participants who were likely to be readers. Attendance at KBC is based on paid registration which may be done weekly or monthly, and the monthly cost of registration for a child would be the equivalent of about 20 per cent of the monthly salary of an average middle-income person in Nigeria. That means the children who attend the KBC were from high-income homes. There were fifteen participants in the study, seven boys and eight girls, and they all attended different private, fee-paying schools. Secondary participants who contributed to the study were 15 parents representing each child as well as three staff members of the book club.

\section{Methods}

Data were gathered through the qualitative methods of creating visual images (collage-making), observation, questionnaire and interview; secondary participants provided data only through questionnaire. Details of the different methods are below.

\section{(1) Collage-making}

This method was inspired by the 'critical incidents' collage-making used by Cliff Hodges (2010b) in her study of 1213-year-old readers. The purpose of collage-making was to find out the extent to which the participants had engaged in leisure reading in the past year. It required participants using cut-out coloured papers to create a collage of their leisure time activities in the past year. Participants drew a river on white cardboard and divided the river into six sections that represented the three school terms and the three holidays in a year, with a holiday section coming after a school term section. Following a guide (Figure 1) which showed what activity each colour represented, participants pasted on each section cut-out coloured papers that indicated both the activities they had spent time on and the amount of time they believed they had spent on the activity.

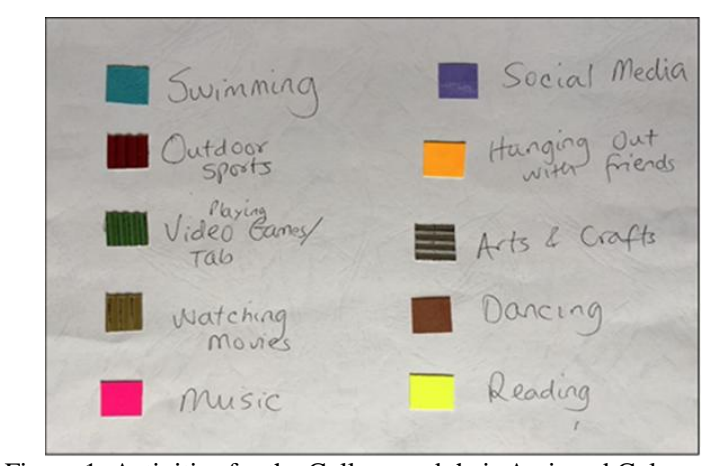

Figure 1: Activities for the Collage and their Assigned Colours

Thus, the more time a participant spent on a particular activity, the more the activity's assigned coloured paper featured on the participant's collage. 


\section{(2) Observation}

Physical space could affect children's attitudes to reading (Loh, 2015) and strategies such as making books visible and creating programmes to excite readers encourage reading (Loh et al., 2017). Observation was used to identify details of the book club, the reading environment it provided, the network of resources that support reading it offered, and to determine how much the physical space of the book club enhanced the participants' engagement with leisure reading. The observations were written down as fieldnotes.

\section{(3) Questionnaire}

The study employed a qualitative questionnaire to generate data from participants, their parents and the staff of KBC, therefore three different questionnaires were designed and administered. The questionnaires generated data on the participants' reading habits including the extent to which they read, their reading behaviours, attitudes to reading, estimates of their reading frequencies, books read, out-of-school activities, and the influence of the participants' home environments and $\mathrm{KBC}$ on the children's reading habits.

\section{(4) Interview}

The forms of interview used were face-to-face semi-structured group interviews and semi-structured individual interviews. The interview schedules had both open-ended and close-ended questions which explored the reading habits of the participants; how what, when and why they read when they read at KBC, at home and in their schools; and the different factors that affected the reading engagement of the participants; and what reading-supporting social networks were available to the participants. The length of the interviews varied, with most lasting for between 30 and 40 minutes. To ensure a range of views, each group interview had between five and seven participants.

\section{Data Analysis}

The collages were analysed in terms of the activities represented by the colour-coded papers. This involved counting the total number of paper pieces on each collage and the number of each of the different coloured paper pieces on the collage, and then working out the percentage of the collage that each colour represented. Analysis of the collages was converted into texts. All the interviews were fully transcribed and data from questionnaires and observation were fully written up. All the data were analysed through inductive thematic analysis following Braun \& Clarke's (2006) guide to doing thematic analysis. The data was repeatedly looked through for familiarisation, the data sets were broken into smaller units, and each unit was carefully reviewed several times to generate codes. The codes generated were relevant to the research questions and were sorted and collated into themes which were carefully reviewed to see what story they told about the data. Cross-case analysis was also done to identify recurring themes as well as note differences in the different data.

\section{RESULTS}

Findings from the data indicate that the participants read for pleasure, though their level of engagement with reading for pleasure differed. The findings also reveal that to varying degrees, the reading engagement of all the participants was affected by different factors.

\section{A. The Extent to Which the Children Read}

The collages of the participants, some of which are Figures 2, 3, 4 and 5 below, reveal that all the participants did leisure reading, but differed in the extent to which they read. In the collages, leisure reading is represented by the yellow colour:

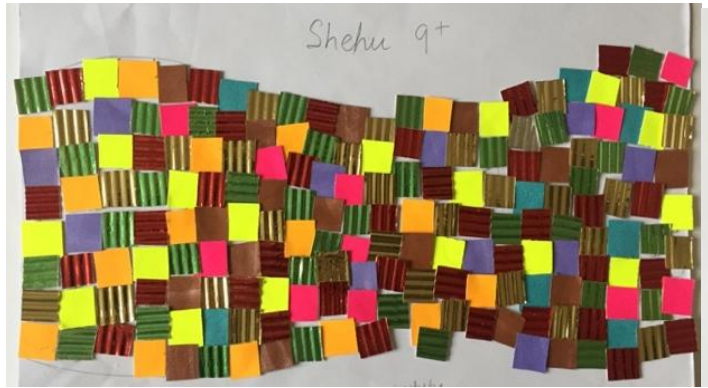

Figure 2: Shehu's collage

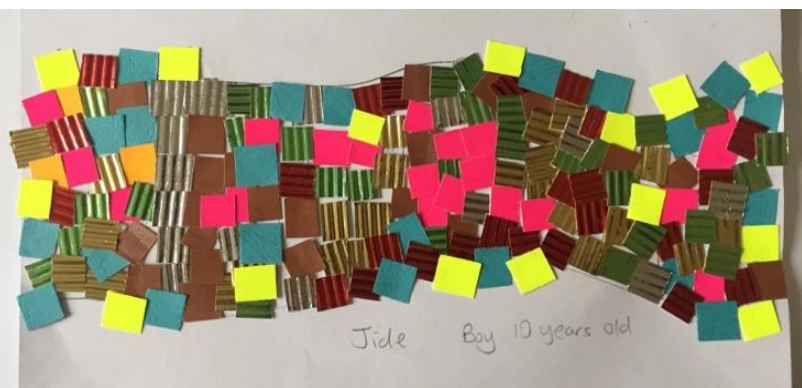

Figure 3: Jide's collage 


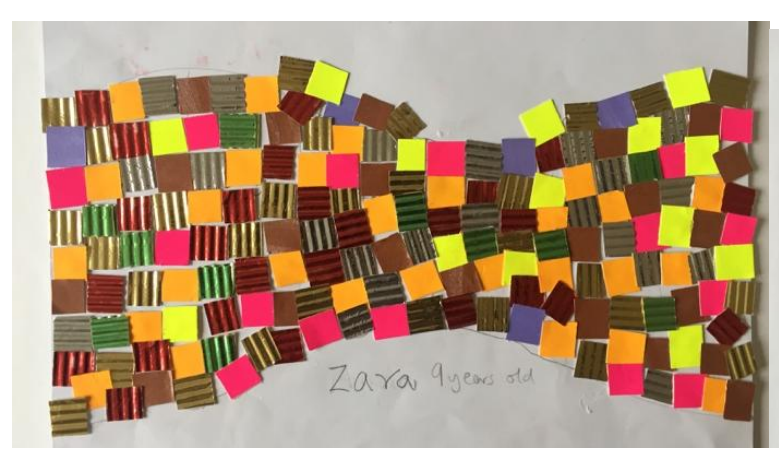

Figure 4: Zara's collage

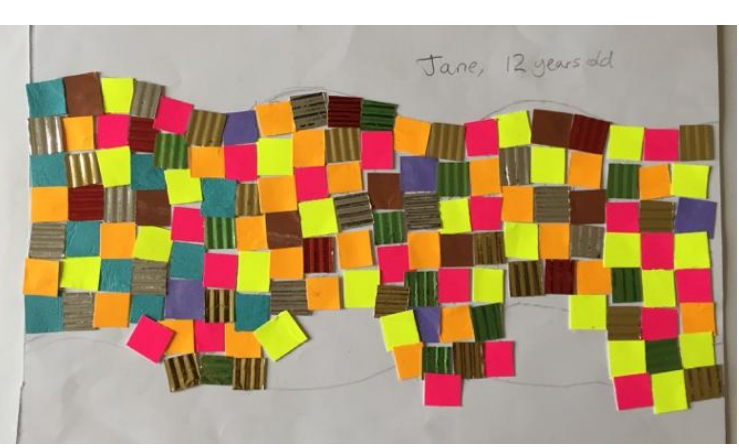

Figure 5: Jane's collage

Data from observation, interview and questionnaire also indicate that the participants had a range of reading engagement and attitudes. Some of the children were engaged readers who read a lot, the majority of participants read moderately, and a few read minimally. Most participants spent about 30 minutes reading each time they read, a few read for a longer period, while others read for a much shorter time. Some participants only read printed materials, but most of them read printed as well as electronic materials, and a few listened to audiobooks in addition to reading both printed and electronic materials. The popular reading materials read included fiction, comics, crime and detective books, adventure books, and factual books. Some of the favourite authors for these children included Jeff Kinney, R. L. Stine, Geronimo Stilton, Shakespeare, Ben Carson, Enid Blyton and Roald Dahl. The participants had different motivations for reading, but many stated that reading was fun and interesting.

\section{B. Factors that Affected the Children's Reading Engagement}

In this section, the different factors that affected the reading habits of the participants will be analysed. It is important to emphasise that the extent to which each participant was affected by the different factors varied. For instance, for each participant, the access to reading materials depended on how well-off the participant's parents were such that the richer the participant's parents, the more reading materials were available to the participant and vice versa.

\section{(1) Pedagogy of Reading}

The present study is in line with studies conducted by Layne (2015) and Rosenblatt (1978/1994) which indicate that children's attitude to reading and literary texts is often affected by the reading practices used. In the data of both group and individual interviews, the theme of being asked questions after leisure reading repeatedly came up. For most of the participants, there was no reading aloud at school; however, almost all the participants who attended schools where teachers read to the class, reported that after the reading aloud sessions, the teachers usually asked questions. The practice of asking children questions during or after reading aloud sessions was also used at KBC. The participants were unequivocal in stating that they did not like being asked questions after leisure reading. Peter likened the experience to being given an exam or a test to write, which suggests that he was no longer listening for the pleasure the experience gave, but to be better prepared to answer the questions that would follow.

The practices of asking questions after reading also affected the participants' attitude to the literary texts read in class. Paul narrated that even though he liked certain books used at school and thought they were interesting, he did not want to read them as the books had questions that his teacher usually made them answer. This shows that the pedagogical practices of reading used could discourage children from reading a book even when the children found the books engaging. It also supports Pennac's (2006) advocacy that children should be allowed to read purely for the pleasure that reading gives rather than as a means of teaching literacy skills as doing otherwise would make the child cease associating reading with pleasure, which may have the likely consequence of making the child stop reading.

\section{(2) Choice of Texts}

Findings from this study support the arguments that the opportunity to choose the texts they read greatly affects children's motivation to read (Clark \& Phythian-Sence, 2008; Cremin, 2015) and that children will more likely read books that they have selected for themselves (Cremin, 2007). All the participants said that they always self-selected the books they read at KBC and were free to change the books at any time. Most participants also self-selected the books they read for pleasure at home. However, in Mike's case, his father usually chose the books he read at home during the holidays, most of which Mike did not like but was still forced to read. Mike described the books his father gave him to read as 'hard books'. He liked Enid Blyton books, but his father did not allow him to read these. In Mike's collage (Figure 6), yellow, the colour that represents reading, is missing in the holiday sections even though it features prominently in the school term sections. 


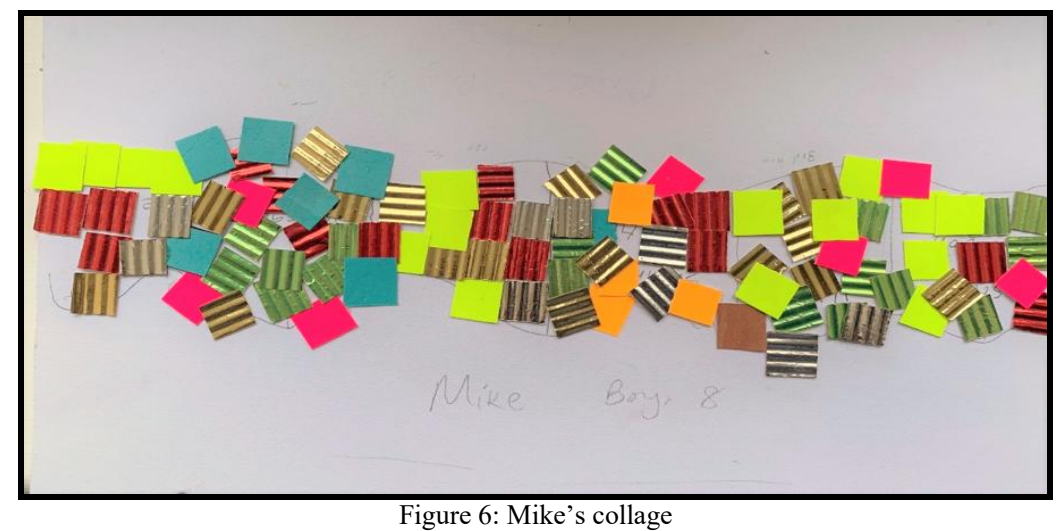

When asked about this during the collage-making activity, Mike said he did not do any leisure reading during the holiday periods; data from his interview further confirmed that he did not enjoy the reading he did at home. This may likely be because the home readings were done at his father's behest and involved books chosen by Mike's father. It is possible that by stopping Mike from reading the books which Mike liked and forcing him to read the books he did not like, Mike's father was reducing Mike's potential to engage in leisure reading.

Adanna self-selected the books she read but complained that her father stopped her from reading Jeff Kinney's Diary of a Wimpy Kid (DOAWK) books because "they don't teach anything." However, this did not appear to negatively impact on her reading engagement as data from her collage, questionnaire and interview indicated that she was an engaged reader. Perhaps this was because she was allowed to read other books she self-selected. Additionally, she admitted that she still read DOAWK books but only when her father was not around. A few other participants also complained that their teachers chose the books they read during the reading time at school and that usually, they did not like the books and hence did not read them. There's a strong likelihood that the participants may have read the books if they had self-selected them.

\section{(3) Reading Aloud}

Studies indicate that another factor that plays a critical role in children's engagement with reading for pleasure is reading aloud (Layne, 2009, 2015; Lockwood, 2008), and this study examined the participants' experience with this. A few participants said their parents had read to them when they were younger and that this had stirred in them an interest in leisure reading; however, two of these participants were also of the opinion that parents didn't need to read to their children after the children had learned to read. Most participants said that they never had the experience of being read to when they were young. For many participants, outside KBC, no-one read aloud to them. Six participants reported that someone at school, usually the class teacher, sometimes read aloud to their class while two participants reported that someone at home read aloud to them. Many participants claimed that they enjoyed being read to at KBC and that the reading aloud made them interested in reading the book. One of these was Karen:

Karen: Aunty Ese was reading a story that ended up to be (sic) one of Aladdin's story. So, then I now picked up that book, I now found the story and now read it. I now found some other stories in that same book as Rumpelstiltskin.

However, there were also cases when the child did not enjoy the reading aloud because of the reader, as this excerpt from Peter shows:

Peter: Teachers spoil the books for me... they have destroyed it for me... whenever I read on my own, I give it a kind of feeling... I give it some voices... which makes it better for me... But when they are reading it for me, they would use their voices which now makes it very useless.

Interviewer: Okay, if they read those books in an interesting voice would it make you more interested in reading them?

Peter: Yes....It also depends on the teacher.

Peter's responses suggest that for him, the meaning of the texts possibly lay in how the texts were read by the reader. His use of strongly negative words to describe the reading aloud done by his teachers indicates that he did not enjoy the reading aloud; howbeit, it was not because of the books involved, but because of the manner and the voice used by the teacher(s). When Peter read, he gave voices to the different characters and this, it is believed, made the characters more real to him, and allowed him to experience the reading in a deeper and more pleasurable way. The finding from Peter indicates that in addition to using suitable and engaging texts for reading aloud, the reader should read in a manner that is engaging and exciting to the listener.

(4) Access to Engaging Books

The study findings indicate that access to engaging texts may also have affected the extent to which the participants read. These results agree with Lockwood (2008) who identified access to suitable and engaging texts as another key factor in motivating children to read. When asked if they usually had access to the books they wanted to read, six children responded with a 'yes' while nine children responded with a 'no'. However, when further questioned about access to books, five of the six children who responded with a 'yes' to the question of access to books said that it was 
not always easy for them to access the texts they wanted to read. Findings suggest that outside KBC, some participants had no access to books that they liked. Access to engaging texts, whether at home or through the school library, was dependent on economic factors. Caleb, whose collage (Figure 7) indicates that he did very little reading in the year, said that he had no books of his own, there were no reading materials in his home, and it was difficult for him to have access to the books he liked.

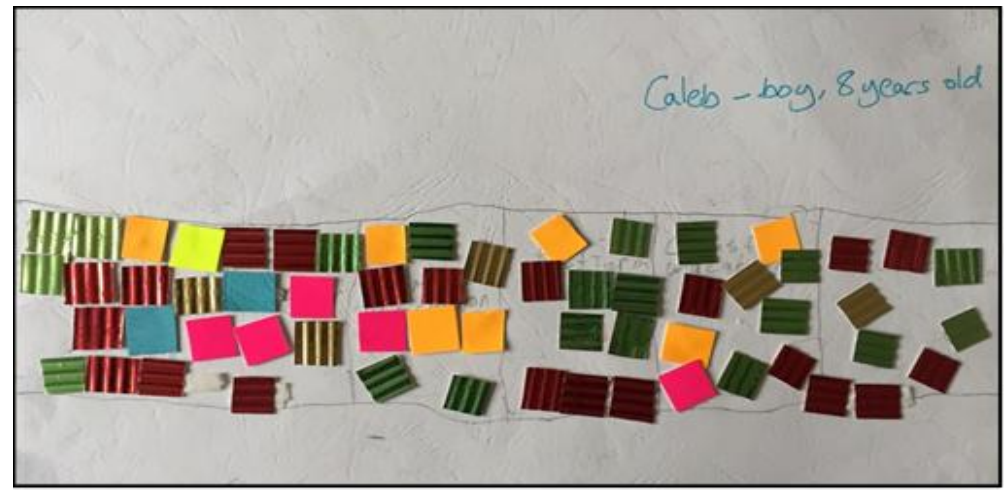

Figure 7: Caleb's collage

On the contrary, participants like Charles and Shehu who had more access to engaging texts at home and at school were more engaged readers; Shehu's collage, Figure 2, is seen in Section 4.1. The limited access to books did not affect every participant in the same way; Odachi was an engaged reader even though she had few reading materials at home and her school library did not have many books. However, she was an outlier here. While the access to reading materials may not guarantee that all children will become engaged readers, the lack of easy access to reading materials certainly discourages children from reading.

\section{(5) An Enabling Adult}

Most of the children in my study said that their parents read a lot, and some discussed books with them. Among the five participants who had someone at home discuss books with them were Karen and Ngozi, and both said that the book discussions encouraged them to read books, supporting the argument on the importance of an enabling adult in a child's reading engagement (Chambers, 1991). Data from Karen's collage, questionnaire and interview indicate that she was a very engaged reader whose favourite pastime was leisure reading; this may have been because she had an enabling adult

A few participants had enabling adults that were non-parents. For instance, Paul's 19-year-old brother was an engaged reader who showed much interest in Paul's leisure reading and often discussed books with Paul. A few participants stated that their teachers sometimes discussed the books they had read with the class. Unfortunately, for some participants, it was only at KBC that they had an enabling adult as neither their parents nor teacher showed much interest in their reading. In addition to reading aloud to the children, staff members at KBC discussed books regularly with the children and suggested texts to them. Some of the children reported that they enjoyed reading the books recommended by staff members. An example is Charles, another engaged reader:

Charles: Usually, the books Aunty Lizzy suggests are really interesting, like The Titanic.

Through book discussions and recommendations, Aunty Lizzy guided Charles to books he found engaging and thereby helped him do more leisure reading than he may have ordinarily done. This supports the argument that an enabling adult could help children read more.

\section{(6) The Reading Environment}

Chambers (1991) argues that where readers read affects how they read and their pleasure, willingness and concentration, and recommends that a suitable reading environment be created for children. Although he does not include the weather in his definition of the reading environment as shared in the 'Literature Review' section, findings from this study suggest the inclusion of the weather as it is a part of the features of a place and also featured prominently in the data on factors that affected the participants' reading. The subject of the hot weather repeatedly came up as one of the factors that prevented the participants from either reading or completing a book. There were also complaints about not having a comfortable place to read, and about having to read in a noisy place. Shehu reported that he could not read in his home in the daytime and only read at night because his house was "really noisy". In a group interview, participants said their reading engagement was affected when the environment was not comfortable, and that that happened even when the book was interesting. They also said they either read more or enjoyed the book better when they were in the right reading environment:

Interviewer: If you had an interesting book and a comfortable place would you read more?

Charles: Yes. Because in my school, my homework was to read but I still liked the book so when I was reading it, they said read for 30 minutes. I timed myself... I ended up reading more than 30 minutes, for 40 minutes because of how comfortable and interesting the book was. 
Interviewer: If you read in those places [the ideal reading environment he described], do you find out that you tend to read longer than if you read anywhere else?

Paul: Well, I enjoy the book better.

These findings on how the reading environment affected the participants' reading practices suggest that the participants may have done more leisure reading if they always had the ideal reading environment.

\section{(7) Social Networks and Affordances that Support Leisure Reading}

Among the social networks and affordances that support leisure reading are school libraries and public libraries, and schools can promote leisure reading by providing easy access to plenty of suitable texts (Lockwood, 2008). Even though the children in my study attended schools that had a library, the libraries varied in size and in how many books they had. Schools that charged more fees had bigger and better-equipped libraries, and vice versa. Additionally, the schools differed in the rules and policies that governed the students' use of the library. Some participants attended schools where students were not allowed into the library, others attended schools where students could visit the library but were not allowed to borrow books, and others were in schools where students could visit the library and borrow books from the library. For instance, in Rose's school, the children were not allowed into the library; the headmistress randomly selected books and gave the children to read, and the children had no say in this. Sometimes, Rose liked the book she was given and read it, and at other times, she did not like the book and did not read it. In some of the school libraries, there were no spaces designed for reading. Therefore, though school libraries have the potential to encourage children to read and build a reading culture, in the schools my study participants attended, this potential was yet to be fully activated and realised.

Public libraries help to close the book gap between children of different backgrounds by providing all children with access to high-quality reading materials (Celano \& Neuman, 2001). Also, they could offer literary activities such as author readings and summer reading groups which nurture children's love for reading (Krolak, 2005). Sadly, apart from one participant, the children in my study had never been to a public library and did not know of any as these are not common in Nigeria. Adanna, the only participant who had visited a public library, reported that she had only been there once, and this, a while back, suggesting that she may not have found the experience worthwhile enough to return to the library.

\section{DisCUSSIONS}

As the results reveal, the reading engagement of all the participants was, in varying degrees, influenced by factors such as the pedagogy of reading, choice of texts, and reading aloud. Findings indicate that some participants were negatively impacted by the pedagogy of reading both at home and in school. Specifically, the practices of asking children questions after reading demotivated the children. Accordingly, one strategy to get children to do more leisure reading might be to change the pedagogical practices of reading and allow children to read solely for the pleasure found in the activity as suggested by Pennac (2006).

Findings from this study support the argument that children should be encouraged to read what they enjoy reading in whatever format they prefer as doing otherwise may reduce the potential for pleasurable engagement in reading (Cremin, 2015). Participants like Mike whose collage (Figure 6 in Section 4.2.2) indicate that he did not do leisure reading during the vacation periods, may have done more recreational reading if he had been allowed to always selfselect the books he read at home. Therefore, another strategy that could motivate children to read is allowing them to select the texts they read. The experience of having someone read aloud to them also affected the children's reading engagement. However, while participants like Karen were driven to read the books they had heard read aloud, a few like Peter did not enjoy being read to, primarily because of the reader's reading style. Hence, it is important to note that while reading aloud has the potential to whet in children an appetite for books (Layne, 2009, 2015), its benefits are best realised when the activity is done by an experienced reader whose voice and manner of reading are appealing to the listener(s).

The participants reading habits were also affected by their access to engaging reading materials, supporting the argument on the importance of access to suitable reading texts (Clark \& Douglas, 2011). While at KBC, all the participants spent significant time in leisure reading as they had easy access to reading materials. However, outside $\mathrm{KBC}$, not all the participants usually had access to the books they wanted to read suggesting that children whose parents could not afford to register them at a book club may not have easy access to engaging reading materials. Making reading materials easily accessible to children is another strategy to encourage them to do more leisure reading. This study supports the argument that an enabling adult plays a key role in helping children to read more (Cremin et al., 2014; Cliff Hodges, 2010b); the example of Charles and Aunty Lizzy in Section 4.2.5 beautifully demonstrates this. Therefore, it is recommended that adults read and discuss books with children as these will help the children discover the joy in reading books.

Another factor that affected the participants' reading engagement was the reading environment. Where the participants had the right reading environment, they better enjoyed their leisure reading and read for a longer time, whereas the reverse was the case where the environment was not conducive for reading. Accordingly, creating the right reading environment could be another strategy to get children to do more recreational reading (Chambers, 1991; Cremin et al., 2014). Findings from this study also support the argument that social networks such as school libraries, public 
libraries and literary programmes which support leisure reading could positively impact on the reading behaviours of children (Loh et al., 2017; Campbell-Hicks, 2016; Adkins \& Brendler, 2015). As already stated, most participants had limited access to these networks and only one participant had visited a public library. Whilst data indicate that being at KBC boosted the participants' reading engagement, the children may have done more leisure reading if they had the opportunity of benefitting from the many literary exposures and experiences that a public library could offer. This study supports the argument for public libraries that have great quantities of a wide variety of high-quality books of various topics, genres, and perspectives, and offer literary activities as this will help to nurture in children a love for leisure reading.

\section{FUTURE RESEARCH DIRECTIONS}

The reading environment provided by the book club may likely have influenced how much reading the children did. It is therefore recommended that the same study be constructed with similar participants in a different location, one that does not provide an environment that supports leisure reading. Findings from this new study could show the extent to which my study's findings were affected by the reading environment provided by $\mathrm{KBC}$, and more importantly, would give useful insights about how children read in locations that are not set up to support reading. Book clubs are not very common features in Nigeria and hence, the vast majority of children in Nigeria have never been to one. Conducting a similar study outside a book club will therefore give further understanding of how the majority of children in Nigeria read during the vacation periods.

Even though this research was rigorously carried out, the findings cannot be generalised as the participants represent only a portion, a small one at that, of Nigerian children. Further research focusing on children who attend public schools and/or children who live in rural settings is recommended. Children who come from less privileged backgrounds than my study's participants will probably have fewer of the social networks and affordances that support leisure reading than my study's participants do; however, it is still important to examine and know what specifically is available to these children to understand their reality and come up with strategies that will have a positive impact on them, too.

\section{CONCLUSION}

This paper has provided insights into some of the factors that affected the participants' reading engagement. Specifically, the paper has discussed how the reading engagement of participants was affected by the pedagogy of reading, choice of text, reading aloud, access to reading materials, an enabling adult, the reading environment and the availability of social networks and affordances that support leisure reading. These insights will help parents and educators to reappraise their support of children's reading habits and adopt practices that will encourage children's appreciation of reading. This, it is believed, will help more children in Nigeria to do more leisure reading and, ultimately, lead to a strengthening of Nigeria's education system and an improvement in student attainment. Additionally, this research provides empirical evidence from Nigeria to complement the wealth of research in the Western world.

\section{ACKNOWLEDGEMENTS}

I would like to sincerely thank the director and staff members of 'KBC' and the participants of the study for allowing me into their world. I also thank Ubong Awah and Gabrielle Cliff Hodges for their support during this research.

\section{REFERENCES}

[1] Adekunle (2017, June 21). Study shows Nigerians don't read. Vanguard. https://www.vanguardngr.com/2017/06/study-showsnigerians-dont-read/ (accessed 10/09/2020).

[2] Adesulu, D. (2016, March 24). 80\% fail NECO, WAEC, JAMB over the dearth of reading culture — Ignite Africa. Vanguard. http://www.vanguardngr.com/2016/03/80-fail-neco-waec-jamb-dearth-reading-culture-ignite-africa/ (accessed 15/09/2020).

[3] Adesulu, D. (2018, July 4). Breaking: WAEC releases 2018 WASSCE results as 50\% pass Math, English. Vanguard. https://www.vanguardngr.com/2018/07/breaking-waec-releases-2018-wassce-results-as-50-pass-math-english/) (accessed 15/09/2020).

[4] Adkins, D., \& Brendler, B. M. (2015). Libraries and reading motivation: A review of the Programme for International Student Assessment reading results. IFLA Journal 41(2): 129-139. doi: 10.1177/0340035215578868.

[5] Aramide, K. A. (2015). Effect of parental background factors on reading habits of secondary school students in Ogun state, Nigeria. Journal of Applied Information Science and Technology, 8(1), 70-80. https://www.jaistonline.org/vol8_no1_Aramide.pdf (accessed 10/09/2020).

[6] Barrs, M., \& Cork, V. (2001). The Reader in the Writer. London: Centre for Language in Primary Education.

[7] Braun, V., \& Clarke, V. (2006). Using thematic analysis in psychology. Qualitative Research in Psychology, 3(2), 77-101. https://doi.org/10.1191/1478088706qp063oa.

[8] Campbell-Hicks, R. (2016). Early literacy programmes in public libraries: best practice. The Australian Library Journal, 65(2), 121-129. doi: 10.1080/00049670.2016.1121770. 
[9] Celano, D., \& Neuman, S. (2001). The Role of Public Libraries in Children's Literacy Development: An Evaluation Report. Pennsylvania Library Association Technical Report, Pennsylvania Department of Education. http://citeseerx.ist.psu.edu/viewdoc/download?doi=10.1.1.611.4915\&rep=rep1\&type=pdf (accessed 26/09/2020).

[10] Chambers, A. (1991). The Reading Environment: How Adults Help Children Enjoy Books. Stroud: Thimble Press.

[11] Chambers, A. (1993). Tell Me: Children, Reading and Talk. Stroud: Thimble Press.

[12] Chew, P. G., \& Krashen, S. (2017). Vocabulary acquisition and self-selected reading: a test of the reading hypothesis in Singapore. The International Journal of Foreign Language Teaching, 12(2), 1-7. http://ijflt.com/images/ijflt/articles-december2017/Research\%20Art\%201\%20Vocabulary.pdf (accessed 10/09/2020).

[13] Clark, C. (2013). Children's and Young People's Reading in 2012. Findings from the 2012 National Literacy Trust's annual survey. London: National Literacy Trust. https://literacytrust.org.uk/research-services/research-reports/childrens-and-youngpeoples-reading-2012/ (accessed 10/09/2020).

[14] Clark, C., \& Douglas, J. (2011). Young People's Reading and Writing: An In-Depth Study Focusing on Enjoyment, Behaviour, Attitudes and Attainment. London: National Literacy Trust. https://files.eric.ed.gov/fulltext/ED521656.pdf (accessed 10/09/2020).

[15] Clark, C., \& Phythian-Sence, C. (2008). Interesting Choice: The (Relative) Importance of Choice and Interest in Reader Engagement. London: National Literacy Trust. https://literacytrust.org.uk/research-services/research-reports/interesting-choicerelative-importance-choice-and-interest-reader-engagement-2008-review/ (accessed 26/09/2020).

[16] Cliff Hodges, G. (2010a). Reasons for reading: why literature matters. Literacy, 44(2), 60-68. doi:10.1111/j.17414369.2010.00552.x.

[17] Cliff Hodges, G. (2010b). Rivers of reading: Using critical incident collages to learn about adolescent readers and their readership. English in Education, 44(3), 181-200. doi: 10.1111/j.1754-8845.2010.01072.x.

[18] Cliff Hodges, G., (2011). Textual drama: the value of reading aloud. English Drama Media, 19, 19-25.

[19] Coles, M., \& Hall, C. (2002). Gendered readings: learning from children's reading choices. Journal of Research in Reading, 25(1), 96-108. doi:10.1111/1467-9817.00161.

[20] Cremin, T. (2007). Revisiting reading for pleasure: Delight, desire and diversity. In K. Goouch \& A. Lambirth (Eds.), Understanding Phonics and the Teaching of Reading: A Critical Perspective (pp. 166-190). Berkshire, UK: McGraw Hill.

[21] Cremin, T. (2015, September 25). Requiring Reading for Pleasure. Cambridge Primary Review Trust. http://cprtrust.org.uk/cprt-blog/requiring-reading-for-pleasure/ (accessed 10/08/2020).

[22] Cremin, T., Mottram, M., Collins, F. M., Powell, S., \& Safford, K. (2014). Building Communities of Engaged Readers: Reading for Pleasure. London: Routledge.

[23] Crotty, M. (1998). The Foundations of Social Research: Meaning and Perspective in The Research Process. London: Sage.

[24] Cullinan, B. E. (2000). Independent reading and school achievement. School Library Media Research, 3, 1-24. http://www.ala.org/aasl/sites/ala.org.aasl/files/content/aaslpubsandjournals/slr/vol3/SLMR_IndependentReading_V3.pdf (accessed 10/09/2020).

[25] Cunningham, A. E., \& Stanovich, K. E. (1998). What reading does for the mind. American Educator, 22(1\&2), 8-15. https://www.researchgate.net/publication/237109087_What_reading_does_for_the_mind (accessed 10/09/2020).

[26] Data World Bank. (2016). Nigeria Data. Data World Bank. https://data.worldbank.org/country/nigeria (accessed 16/08/2020).

[27] Data World Bank. (2020). Population, total - Nigeria. Data World Bank. https://data.worldbank.org/indicator/SP.POP.TOTL?locations=NG (accessed 20/09/2020).

[28] Francois, C. (2015). An urban school shapes young adolescents' motivation to read. Voices from the Middle, 23(1), 68-72. https://www.ncte.org/library/NCTEFiles/Resources/Journals/VM/0231-sep2015/VM0231Urban.pdf (accessed 10/09/2020).

[29] Gordon, J. (2018, June 21). Teaching to ensure literature's lasting impression. The British Academy. https://www.thebritishacademy.ac.uk/blog/teaching-ensure-lasting-impression-literature (accessed 20/08/2020).

[30] Haliru, R. A., Abdulkarim, M., Mohammed, A. D., \& Dangani, B. U. (2015). An assessment of reading habit among secondary school students in Kaduna metropolis. IOSR Journal of Humanities and Social Science (IOSR-JHSS), 20(10), 12-17. DOI: $10.9790 / 0837-201021217$.

[31] Ihejirika, R. C. (2014). Poor attitude to reading for pleasure and its implications on the acquisition of language skills and academic achievements: the case of students of secondary schools in Nigeria. IOSR Journal of Humanities and Social Science (IOSR-JHSS), 19(1), 43-46. http://iosrjournals.org/iosr-jhss/papers/Vol19-issue1/Version-10/G0191104346.pdf (accessed 10/09/2020).

[32] Ilogho, J. E., \& Michael-Onuoha, H. C. (2015). Intervention strategies for combating aliteracy in Nigerian schools: Implications for public libraries and government. International Journal of Academic Research in Education and Review, 3(3), 58-64. doi: 10.14662/IJARER2015.015.

[33] Kinney, J. (2007 - 2017). Diary of a Wimpy Kid. [Book Series] London: Puffin Books.

[34] Klauda, S. L. (2009). The role of parents in adolescents' reading motivation and activity. Educational Psychology Review, 21(4), 325-363. https://doi.org/10.1007/s10648-009-9112-0.

[35] Krolak, L. (2005). The role of libraries in the creation of literate environments. Paper commissioned for the EFA Global Monitoring Report 2006, Literacy for Life. https://www.ifla.org/files/assets/literacy-and-reading/publications/role-of-librariesin-creation-of-literate-environments.pdf (accessed 20/09/2020).

[36] Layne, S. (2009). Igniting a Passion for Reading: Successful Strategies for Building Lifetime Readers. Portland, Maine: Stenhouse Publishers.

[37] Layne, S. (2015). In Defense of Read-Aloud: Sustaining Best Practice. Portland, Maine: Stenhouse Publishers.

[38] Lockwood, M. (2008). Promoting Reading for Pleasure in the Primary Classroom. London: Sage.

[39] Loh, C. E. (2015). Building a Reading Culture in a Singapore School: Identifying Spaces for Change Through a Socio-spatial Approach. Changing English, 22(2), 209-221. doi: 10.1080/1358684X.2015.1022509.

[40] Loh, C., Ellis, M., Paculdar, A., \& Wan, Z. (2017). Building a successful reading culture through the school library: A case study of a Singapore secondary school. IFLA Journal, 43(4), 335-347. doi: 10.1177/0340035217732069. 
[41] Makinde, F. (2018, June 1). National Library to promote reading culture. Punch. https://punchng.com/national-library-topromote-reading-culture/ (accessed 20/09/2020).

[42] Manresa, M. (2018). Adolescent Reading Habits: The effect of school activities on reading practices. In Arizpe, E. \& Cliff Hodges, G. (Eds.). Young People Reading: Empirical Research Across International Contexts (pp.123-136). London and New York: Routledge.

[43] Mar, R. A., Oatley, K., \& Peterson, J. B. (2009). Exploring the link between reading fiction and empathy: Ruling out individual differences and examining outcomes. Communications -European Journal of Communication Research, 34(4), 407-428. doi 10.1515/COMM.2009.025.

[44] Mullis, I.V.S., Martin, M.O., Kennedy, A.M., \& Foy, P. (2007). PIRLS 2006 International Report: IEA's Progress in International Reading Literacy Study in Primary Schools in 40 Countries. http://timss.bc.edu/PDF/p06_international_report.pdf (accessed 20/08/2020).

[45] Okebukola, F.O. (2005). Towards an improved reading culture among Nigerian students. Educational Issues, 2(1), 54-64.

[46] Olasehinde, M. O., Akanmode, O. A., Alaiyemola, A. T., \& Babatunde, O. T. (2015). Promoting the reading culture towards human capital and global development. English Language Teaching, 8(6), 194-200. doi:10.5539/elt.v8n6p194.

[47] Onukaogu, C. E. (2001). Teacher effectiveness as a factor in the reading empowerment of the nursery and elementary school African child. In Proceedings of the 1st Pan-African Reading for All Conference (pp. 181-192). International Reading Association/UNESCO. https://unesdoc.unesco.org/ark:/48223/pf0000151834 (accessed 10/09/2020).

[48] Oyewusi, F., \& Ayanlola, A. O. (2014). Effect of mobile phone use on reading habits of private secondary school students in Oyo State, Nigeria. School Libraries Worldwide, 20(1), 116-127. doi: 10.14265.20.1.008.

[49] Parry, B., \& Taylor, L. (2018). Readers in the round: children's holistic engagements with texts. Literacy, 52(2), 103-110. doi: 10.1111/lit.12143.

[50] Pennac, D. (2006). The Rights of the Reader. London: Walker Books.

[51] Rosenblatt, L. M. (1978/1994). The Reader, The Text, The Poem: The Transactional Theory of The Literary Work. Carbondale \& Edwardsville: Southern Illinois University Press.

[52] Sotiloye, B. and Bodunde, H. (2018). Assessment of students' reading culture in a Nigerian university: Waxing or waning? Legon Journal of the Humanities 29.2 (2018) DOI: https://dx.doi.org/10.4314/ljh.v29i2.11.

[53] Sullivan, A., \& Brown, M. (2015). Reading for pleasure and progress in vocabulary and mathematics. British Educational Research Journal, 41(6), 971-991. doi:10.1002/berj.3180.

[54] Tunde-Awe, B. M. (2014). Relationship between Reading Attitudes and Reading Comprehension Performance of Secondary School Students in Kwara State, Nigeria. Review of Arts and Humanities, 3(2), 203-215. https://pdfs.semanticscholar.org/a542/8255ac2f085b2832c6c15da597dc6a8867a6.pdf (accessed 10/09/2020).

[55] World Bank Report No: 115391-NG. (2017). Program Appraisal Document On A Proposed Credit In The Amount Of Sdr 445.7 Million To The Federal Republic Of Nigeria For A Better Education Service Delivery For All Operation. http://documents.worldbank.org/curated/en/839251498183393835/pdf/BESDA-PAD-May-30-2017-06012017.pdf (accessed 20/08/2020).

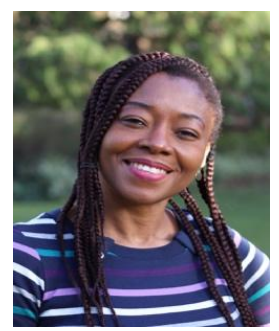

Isang U. Awah was born in Nigeria, Africa. She holds a Bachelor of Science degree in biochemistry from the University of Uyo, Nigeria (1991), a Master of Liberal Arts in Extension Studies degree (literature \& creative writing; 2011) from Harvard University, United States of America, and a PhD in education (2019) from the University of Cambridge, United Kingdom.

She is a project manager in the Department of Social Policy and Intervention at the University of Oxford and specifically works on the development of the Parenting for Lifelong Health Digital (PLH Digital), a digital version of the in-person parenting programme. The project is part of the UKRI GCRF Accelerating Achievement for Africa's Adolescents Hub. Her research interests include social issues and literacy especially in developing countries and poor communities around the globe. She has over a decade of experience in researching with children and young people in Africa and has carried out studies on various topical issues such as the effects of verbal abuse on female domestic servants in Nigeria.

Dr. Awah has presented her research at several international conferences including the 54th UK Literacy Association (UKLA) International Conference, Cardiff (2018) and the 10th International Conference on Education and New Developments (END), Portugal, (2019). 